Article

\title{
The Impact of Brain Lateralization and Anxiety-Like Behaviour in an Extensive Operant Conditioning Task in Zebrafish (Danio rerio)
}

\author{
Maria Elena Miletto Petrazzini ${ }^{1, *}$, Alessandra Pecunioso ${ }^{2}$, Marco Dadda ${ }^{2}$ and \\ Christian Agrillo 2,3 (D) \\ 1 School of Biological and Chemical Science, Queen Mary University of London, London E1 4NS, UK \\ 2 Department of General Psychology, University of Padova, 35131 Padova, Italy; \\ alessandra.pecunioso@studenti.unipd.it (A.P.); marco.dadda@unipd.it (M.D.); \\ christian.agrillo@unipd.it (C.A.) \\ 3 Padova Neuroscience Center, University of Padova, 35131 Padova, Italy \\ * Correspondence: m.e.milettopetrazzini@qmul.ac.uk
}

Received: 24 September 2019; Accepted: 5 November 2019; Published: 12 November 2019

check for updates

\begin{abstract}
Several studies in mammals, birds, and fish have documented better cognitive abilities associated with an asymmetrical distribution of cognitive functions in the two halves of the brain, also known as 'functional brain lateralization'. However, the role of brain lateralization in learning abilities is still unclear. In addition, although recent studies suggest a link between some personality traits and accuracy in cognitive tasks, the relation between anxiety and learning skills in Skinner boxes needs to be clarified. In the present study, we tested the impact of brain lateralization and anxiety-like behaviour in the performance of an extensive operant conditioning task. Zebrafish tested in a Skinner box underwent 500 trials in a colour discrimination task (red vs. yellow and green vs. blue). To assess the degree of lateralization, fish were observed in a detour test in the presence of a dummy predator, and anxiety-like behaviour was studied by observing scototaxis response in an experimental tank divided into light and dark compartments. Although the low performance in the colour discrimination task did not permit the drawing of firm conclusions, no correlation was found between the accuracy in the colour discrimination task and the behaviour in the detour and scototaxis tests. This suggests that neither different degrees of asymmetries in brain lateralization nor anxiety may significantly impact the learning skills of zebrafish.
\end{abstract}

Keywords: operant conditioning; lateralization; symmetry; scototaxis; comparative perception; fish

\section{Introduction}

Once thought to be a human peculiarity, functional brain lateralization is now accepted as a widespread principle of vertebrates' nervous systems. The compelling evidence that several species display different degrees of lateralization brought many authors to hypothesize that functional brain asymmetries lead to several advantages in neurocognitive systems. For instance, brain lateralization is supposed to avoid the simultaneous activation of incompatible responses or costly duplication of neural circuits with the same function [1,2]. Rogers [3,4] hypothesized that, as the two hemispheres of lateralized individuals could carry out different tasks simultaneously, lateralized individuals may cope better in tasks involving divided attention.

In spite of the large amount of experimental evidence showing that lateralized fish are advantaged in different circumstances [5-10], a high degree of polymorphism in laterality is commonly reported in animal populations, and non-lateralized individuals often outnumber lateralized ones [11-14]. Hence, 
there must be ecological contexts in which either brain lateralization does not provide any advantage or it even represents a potential disadvantage. With respect to this issue, Agrillo et al. [15] found no difference in the efficiency of escape behaviour from a dummy predator as a function of the degree of brain lateralization in goldbelly topminnows. Dadda et al. [16] found that strongly lateralized goldbelly topminnows are less accurate than poorly lateralized ones when required to quickly transfer visual information between the two hemispheres before making a decision about which shoal to join.

The capacity to associate a neutral stimulus to a biologically relevant stimulus is one of the main mechanisms through which animals learn environmental contingencies, a fundamental ability to avoid apparently neutral stimuli associated with negative events, or to reach stimuli often related to positive events. A recent study suggested a link between brain lateralization and learning skills. Fontana et al. [17] found a positive correlation in zebrafish between the degree of motor lateralization in a Y-maze and their performance in a classical conditioning task (Pavlovian fear conditioning). Apart from this study, the issue as to whether lateralization in the animal brain has a positive impact on the efficiency of learning abilities remains almost unexplored.

When dealing with learning abilities, the personalities of individuals are known to play an important role. For instance, a bold individual that explores a given environment more quickly will probably encounter some contingencies faster than an individual that explores it less quickly. The former is hence expected to learn faster than the latter. Similarly, neophilia and spatial exploration are supposed to be personality traits that might correlate directly with learning skills, as such behaviours impact the rate at which individuals encounter the environmental contingencies upon which learning is based (see [18] for a review about personality and cognition). On the contrary, anxiety traits may limit the capacity to explore the environment, both in a laboratory setting and in the natural environment, and presumably reduce the chance to learn. A negative correlation between anxiety and performance in cognitive tasks has been reported in humans [19] and in laboratory studies with animal models (e.g., monkeys [20] and rats [21]).

The negative relation between anxiety traits and performance in cognitive tasks is likely to be more pronounced in one of the most common experimental apparatuses used in comparative psychology, the Skinner box. In these boxes, subjects are singly inserted in small tanks or cages with no shelter. This might represent a limit for highly social species, whose individuals are thought to be anxious when isolated from the rest of the group. Apart from anxiety related to social isolation, an environment without any shelter-as is the case in most Skinner boxes-might lead to low performances by individuals with high levels of anxiety, not because of limited cognitive abilities, but because individuals need a larger amount of time to become accustomed to the experimental apparatus. This could be particularly critical when dealing with cold-blooded vertebrates in Skinner boxes. Indeed, fish, amphibians, and reptiles can be easily satiated and might not need to search for food for a prolonged period. In this sense, given the potential difficulty of training cold-blooded vertebrates in Skinner boxes, it becomes fundamental to assess whether other factors, such as personality traits, do not interfere with the learning process.

In the present paper, we tested the impact of brain lateralization and anxiety-like behaviour in a popular model organism in genetic and developmental biology of vertebrates, the teleost fish Danio rerio [22,23]. Recently, this species has also been widely used to increase comprehension of brain functions [24-26]. There is evidence that zebrafish exhibit different cognitive abilities, such as spatial abilities [27], numerical abilities [28], episodic-like memory [29], and social learning [30]. Taken together, these studies suggest that the cognitive abilities of zebrafish are similar to those described in many other vertebrates.

To achieve our goal, we observed the performance of adult zebrafish in a colour discrimination task (red vs. yellow and blue vs. green), using an extensive operant conditioning procedure. A large body of experimental evidence showed that classical (Pavlovian) and operant (Skinnerian) conditioning rely on different neuro-cognitive systems [31-33]. Therefore, investigating the relation between operant conditioning skills, lateralization and anxiety-like behaviour is expected to provide novel insights in 
the literature [17]. We chose these colours because there is evidence that zebrafish can discriminate between them [34]. Subjects were required to discriminate between two squares differing in colour in order to obtain a food reward. The automated procedure guaranteed a high-throughput conditioning of fish (500 trials for each subject) in a manner similar to the operant conditioning cages that are frequently used with mammals and birds. To assess whether learning skills are impacted by brain lateralization, we measured the degree of lateralization of each subject by using the detour test, a test that permits the establishment of spontaneous preference in the use of one eye over the other in observing a potential predator. This test proved to be extremely reliable in quantifying direction and degree of lateralization in fish, and has been adopted in a large number of studies (e.g., [12,35-39]). Lastly, to assess the role of anxiety in the efficiency of learning a conditioned rule, we adopted one of the most powerful tools used to assess anxiety-like behaviour in animal species, scototaxis; that is, the spontaneous preference for staying in a darker/lighter area of their environment [40-42].

\section{Methods}

\subsection{Subjects}

We preliminarily assessed the sample size using $G^{*}$ Power 3.1 with means and standard deviations taken from our preliminary observations, choosing $\alpha=0.05$ and a desired power of 0.80 . We found a total of 20 subjects was appropriate to test our hypothesis. We accordingly tested 20 adult (older than 5 months) zebrafish (Danio rerio). Four subjects, however, ceased to participate (two in the pre-training phase, and two in the training phase after a few trials) and were discarded from the experiment; hence, the final sample consisted of 16 subjects (nine females, seven males). Fish were taken from a commercial store and were maintained at the Comparative Psychology Department of the University of Padova in mixed-sex groups of 20-30 individuals (150 litres each tank). Aquaria were provided with natural gravel, live plants, air filters, and a 14:10 h light:dark (L:D) photoperiod with an $18 \mathrm{~W}$ fluorescent light placed $11 \mathrm{~cm}$ above the water surface. Both stock tanks and experimental tanks were maintained at a constant temperature of $25 \pm 1^{\circ} \mathrm{C}$. Each day, subjects were fed once with commercial food flakes or with live brine shrimps (Artemia salina). However, food was not provided for 3 hours preceding the beginnings of the experimental sessions to avoid satiation.

Fish were tested 3 months after their arrival into the laboratory. One week before the beginning of the experiment, each subject was inserted in a $50 \times 19 \times 32 \mathrm{~cm}$ tank together with four smaller conspecifics, a condition that permitted us to isolate the subjects without maintaining them in social deprivation. Indeed, as each subject was the largest fish in its tank, we could easily recognize them at the beginning of each experimental session.

The study complies with all laws of the country in which it was performed (Italy) and was supported and approved by the local ethics committee of the University of Padova (permit number: 37/2016).

Three different tasks were performed: colour discrimination task, scototaxis, and detour test. All fish performed the tasks according to a pseudo-random order.

\subsection{Colour Discrimination Task}

In a colour discrimination task, subjects are commonly required to discriminate between two colours in order to obtain a food reward. This represents one of the most frequently adopted tasks in studies using extensive training procedures [43-46].

\subsubsection{Apparatus and Stimuli}

The experimental apparatus consisted of an automated operant conditioning chamber recently developed for small fish (Zantiks AD, Figure 1a). The overall unit size was $22 \times 30 \times 50 \mathrm{~cm}$ (width $\times$ length $\times$ height) and included a computer, software, and the experimental chamber. The chamber measured $14 \times 20 \times 15 \mathrm{~cm}$ and was made up of white plastic walls that permitted the isolation of the 
chamber from the rest of the room. The floor was made of transparent plastic material because the stimuli were presented using a computer screen $(16 \times 10 \mathrm{~cm} ; 60 \mathrm{~Hz}$ refresh rate display) positioned beneath the tank, in correspondence of a short wall of the tank. A previous study showed that zebrafish can solve colour discrimination tasks when the stimuli are presented at bottom of the tank [34]. With the exception of coloured stimuli, no other light was visible in the chamber in order to make the target colours more salient. The apparatus was supplied with a Cisco Wi-Fi router and controlled via a web browser, allowing researchers to operate it with their own laptop. At the end of the experimental session, the results were downloaded in .csv files. The position of the fish ( $x-y$ coordinates) was automatically detected by the integrated computer using an infrared camera above the tank and infrared source below the tank. Water chemistry and water temperature in the chamber were identical to those of the home tanks.
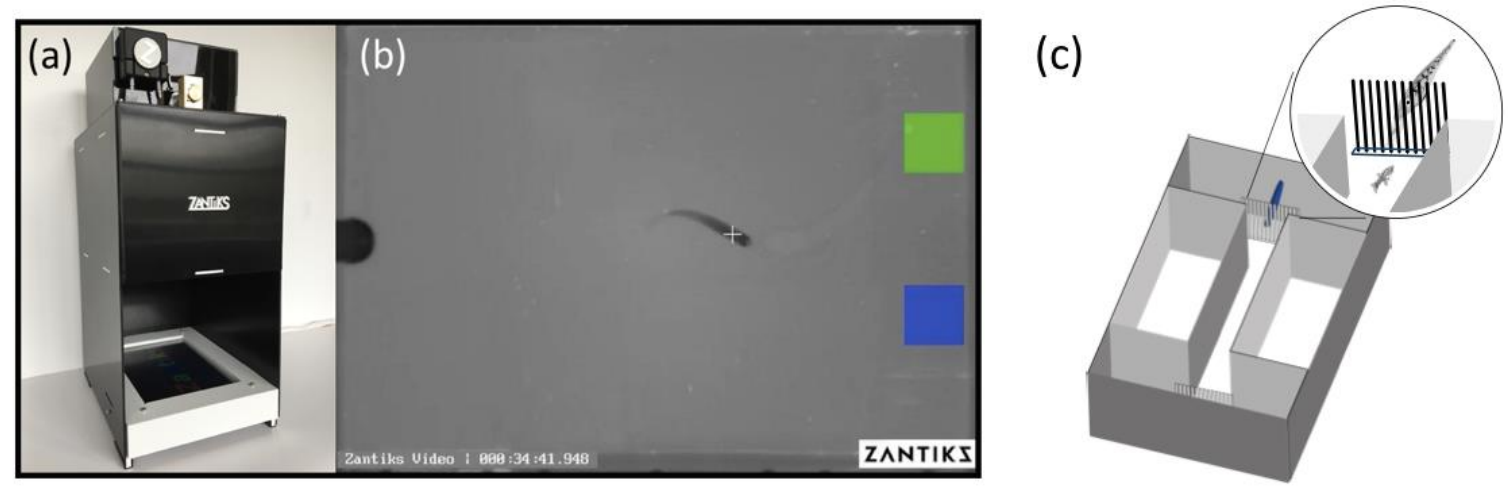

Figure 1. Experimental apparatus. (a) Lateral view of the operant conditioning chamber (Zantiks AD). Stimuli were presented using a screen positioned on the base of the tank. A camera mounted above the tank automatically detected the behaviour of the subject and sent information to a computer through a wireless internet connection. (b) Example of the experimental setting used in the operant conditioning chamber. As soon as the focal fish triggered the beginning of a trial by selecting an initiator light presented on one side of the tank (e.g., left), two squares differing in colour (e.g., green and blue) were presented on the opposite side (right). A correct choice triggered a motor to release food at the opposite end of the tank. (c) Apparatus used to test brain lateralization. The central runway allowed the fish to face a barrier. A dummy predator was visible behind the barrier at the both ends of the runway.

Stimuli consisted of coloured squares $(2 \times 2 \mathrm{~cm}$ ): yellow (RGB: 255, 255, 0), red (RGB: 255, 0, 0), blue (RGB: 0, 0, 255), and green (RGB: 0, 255, 0). The beginning of each trial was characterized by the presence of an initiator white light square (RGB: 255, 255, 255).

\subsubsection{Procedure}

Two different phases were set up:

Pre-Training

The goal of pre-training consisted of ensuring that the subject learned to trigger the presentation of the stimuli and then swam to the feeder and ate the food reward after having selected one stimulus. This phase enabled us to exclude fish that were unable to perform the task at an early stage, ensuring that any eventual lack of discrimination between the colours was not simply due to a general failure to learn how to start a trial and where to reach the food reward.

Each subject was taken from its home tank and moved to the experimental tank. After 5 minutes of initial habituation to the novel environment, we started the pre-training session. It lasted approximately 50 minutes, for a total of 80 trials. Each trial started with an initiator light (white square, $2 \times 2 \mathrm{~cm}$ ) that appeared in correspondence with one short end of the tank and remained visible for a maximum of 10 seconds. Approaching the initiator light (that is, swimming above the white square) triggered the presentation of a coloured square on the opposite end of the tank. In particular, the coloured 
square appeared in the same side of the tank where the two colours to be discriminated against were presented in the training phase. If fish did not select the initiator light, it disappeared and no other light was visible for the next 10 seconds. In these cases, we classified the trial as an 'omission'. The coloured square was green in case of the yellow versus red discrimination; a red square appeared in the case of the green versus blue discrimination. The coloured square remained visible for 10 seconds; if the subject selected it, a $2 \mathrm{mg}$ portion of commercial flake food, GVG Sera, was released in the tank in correspondence with the initiator light. Fish were already familiar with this type of food because they were fed half of the week with this food in their home tanks. The automated release of a controlled amount of food permitted us to tackle the limitation of manual training tasks in which researchers can hardly deliver a standard and very limited amount of food as reward, a fundamental condition for testing cold-blooded species. If the subject did not select the coloured square, the trial was again classified as an 'omission' and a time-out of 10 seconds was presented before the beginning of the next trial. Only fish who completed at least 25 out of 80 trials in a session advanced to the next step. If fish did not reach this criterion within 10 sessions, they were discarded from the experiment.

Training

Half of the subjects $(N=8)$ were trained in a yellow versus red discrimination (yellow as positive stimulus for $50 \%$ of the subjects); half $(N=8)$ were trained in a blue versus green discrimination (green as positive stimulus for $50 \%$ of the subjects).

Each trial started with a white initiator light. If fish triggered the light within 10 seconds, two squares differing in colour appeared on the opposite side of the tank (Figure 1b) in the centre of the two halves of the wall (inter-stimulus distance: $3.5 \mathrm{~cm}$ ). If subjects selected the positive stimulus, a food reward - the same amount used in the pre-training phase-was delivered in correspondence with the initiator light (see supplemental material for a video of a single trial); if subjects selected the negative stimulus, the two stimuli disappeared. The two stimuli remained visible for a total of 10 seconds; if subjects did not select the initiator light or did not select any stimulus, we classified the trial as an 'omission'. A total of 100 trials were presented in a training session; hence, each session lasted approximately 1 hour. The position of the positive stimulus was changed across trials according to a random sequence. When fish performed 500 valid trials (either correct or incorrect-no omissions were included) the task was concluded. To assess the overall learning skills of subjects, we used the criterion previously adopted in fish by Agrillo et al. [47] consisting in computing the average performance of each subject after a fixed number of trials (number of correct choices/total number of trials).

\subsection{Anxiety-Like Behaviour: Scototaxis Test}

Scototaxis refers to the spontaneous dark/light preference of animals and is commonly taken as a valid low-cost tool for assessing anxiety-like behaviour of the subjects under investigation. It is based on the natural aversive quality of brightly lit environments for several species, a fact that leads to a conflict situation in which the subjects have to trade off their natural tendency to explore an environment with the presence of an unpleasant (and potentially dangerous) area [41].

\subsection{Stimuli, Apparatus, and Procedure}

We used the same apparatus used for the colour discrimination task. Fish were singly inserted in the experimental tank for a total of 15 minutes during which they were free to explore the environment. After 5 minutes of acclimation, in which the bottom of the tank was black, half of the floor remained black (RGB: 0, 0, 0) while the other half became white (RGB: 255, 255, 255). Five minutes later, the position of the black and white floors were switched to prevent that any side bias that might have affected the results. The proportion of time spent in the dark compartment (a) and the proportion of movements made in the dark compartment (b) were taken as dependent variables. 


\subsection{Lateralization Test: Detour Test}

Several studies have shown that asymmetries in fish behaviour reflect functional/anatomical asymmetries of the brain, even though the exact reasons underlying such relation are unclear [48-50]. Therefore, the observation of spontaneous behaviour of animals represents a powerful non-invasive tool to assess the degree of their brain lateralization. In the detour test, the fish typically swims along a runway until it faces a barrier behind which a dummy predator is visible (Figure 1c). The direction taken by a fish when leaving the runway depends strictly on its eye preference to look at the dummy predator $[10,15,16,51]$.

\subsection{Stimuli and Apparatus}

A different apparatus was used to measure brain lateralization of zebrafish. We used a modification of the apparatus adopted in several other studies in teleost fish [12,52], which consisted of a glass tank $(60 \times 94 \times 36 \mathrm{~cm})$ covered with plastic. The apparatus was filled with $10 \mathrm{~cm}$ of water. In the middle we built a plastic runway $(7 \times 40 \mathrm{~cm})$ that allowed the zebrafish to face a barrier, behind which a dummy predator was visible at both ends of the runway (Rapala lure no. 18, $18 \times 2.5 \mathrm{~cm}$ ). The features of the dummy predator (e.g., black bars over a clear background) mimicked the appearance of a cichlid (Etroplus canarensis) often found in the same geographic areas of zebrafish [53]. The barrier $(17 \times 17 \mathrm{~cm})$ was made of a series of vertical cylindrical yellow plastic bars $(0.05 \mathrm{~cm}$ diameter, spaced $0.25 \mathrm{~cm})$. Two $18 \mathrm{~W}$ fluorescent lamps placed above both shorter sides $(11 \mathrm{~cm}$ above the water surface) lit the apparatus, a condition that maximized the visibility of the dummy predators.

\subsection{Procedure}

Each subject was individually inserted in the apparatus, was released in the middle of the runway, and was gently pushed using a pair of fishnets at the starting point of the runway. The subject swam along the runway until it faced the barrier. We recorded 10 consecutive trials. We computed an index of lateralization on the basis of the percentage of right and left turns taken by the fish when leaving the runway with the following formula: [(number of rightward - number of leftward)/total number of turns] $\times 100$ ]. Fish with lateralization indexes equal to or larger than 60 (corresponding to $80 \%$ or more rightward turns) were classified as having a right-detour preference, whereas individuals with lateralization indexes equal to or smaller than -60 (corresponding to $80 \%$ or more leftward turns) were commonly classified as having a left-detour preference. Individuals that turned leftward half of the time were classified as non-lateralized. These criteria are commonly adopted in the literature of brain lateralization of fish $[9,10,12,16,52]$.

\subsection{Statistical Analysis}

Data were analysed using SPSS 25.0. All statistical tests were two-tailed, and alpha was set up at 0.05 . Data were normally distributed; therefore, we used parametric statistics (Kolmogorov-Smirnov on the average performance in the colour discrimination task, scototaxis test, and detour test, all $p>0.077$ ). The main analyses were represented by Pearson correlations to establish the relation between learning skills in the colour discrimination task, lateralization measured in the detour test, and anxiety-like behaviour measured in the scototaxis test. Bayes factors were also done to verify the strength of the conclusions of these correlational analyses.

For what concern the colour discrimination task, individual performance was analysed with binomial tests on the frequency of correct and incorrect choices. Group analyses were done using an ANOVA to establish if the type of colour contrast affected the performance. One sample $t$-tests were performed to assess whether subjects' choices differed from chance at group level. In the Scototaxis test, one sample $t$-tests were used to establish whether fish preferred to spend a larger proportion of time near the darker area and whether they tended to be more active in the darker area. An independent $t$-test was performed to establish whether there was any difference as a function of sex. Lastly, in the detour 
test, the presence of a laterality bias at group level was assessed by a one-sample $t$-test; independent $t$-test was used to verify the existence of any potential sex-difference.

\section{Results}

Colour Discrimination Task

Individual analyses (binomial tests) on the frequency of correct choices showed that 5 subjects out of $16(31 \%)$ correctly selected the positive stimulus. Six subjects did not select one stimulus more frequently than chance, and five subjects significantly selected the opposite, negative stimulus (Table 1).

Concerning group analyses, a one-way ANOVA with 'colour contrast' as between-subjects factor found no difference in the overall accuracy between fish tested in the yellow versus red comparison and those tested in the green versus blue comparison $(F(1,15)=1.201, p=0.292$, partial eta squared $\left.\eta^{2} \mathrm{P}=0.079\right)$. We accordingly pooled together the two groups in the following analyses. Zebrafish did not significantly select the positive colour (average performance after 500 trials: mean \pm standard error: $0.460+0.034, t(15)=-1.155, p=0.266$, Cohen's $d=0.289 ;$ Figure 2).

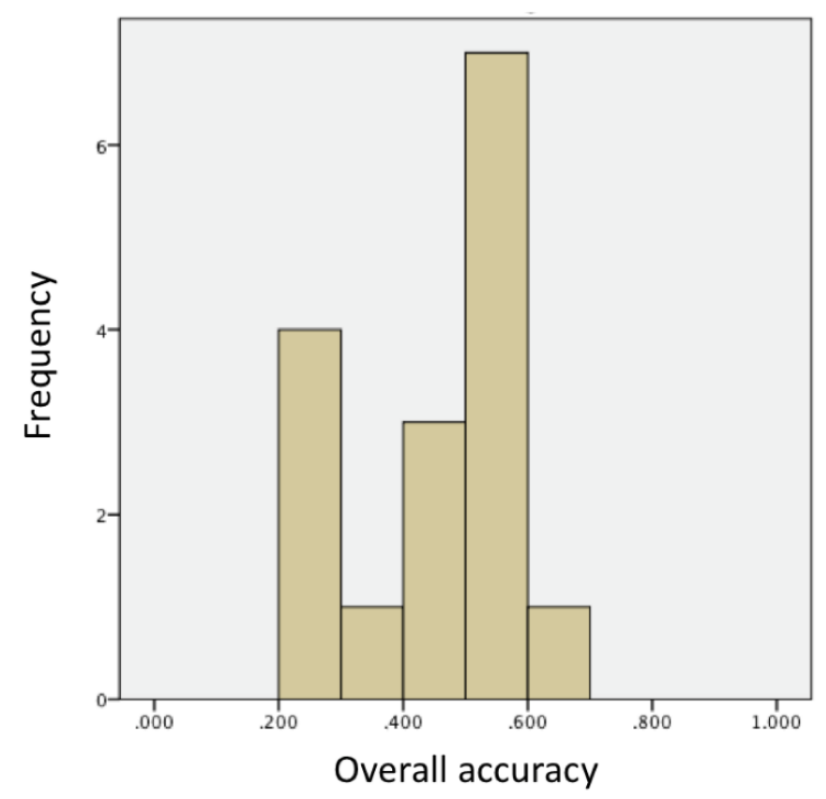

Figure 2. Frequency distribution of accuracy in the colour discrimination task. Five subjects showed discrimination between the two colours.

One may argue that the lack of discrimination at group level was due to the fact that some subjects might exhibit a spontaneous preference for the negative stimulus, thus contrasting their natural tendency to reach a given preferred colour with their capacity to associate the positive colour with the reward. To test this hypothesis, we assessed whether there was any spontaneous preference for joining the colour yellow in the yellow versus red discrimination, and the colour green in the blue versus green discrimination. As we were looking for an untrained colour preference, we analysed the proportion of choices at the very beginning of the training task (first 40 trials). One-sample t-tests showed a significant preference for yellow in the yellow versus red discrimination $(0.640 \pm 0.030$, $t(7)=4.705, p=0.020, d=1.664)$, whereas no preference for any colour was found in the blue vs. green discrimination $(0.558 \pm 0.034, t(7)=1.677, p=0.137, d=0.593)$. Interestingly, four out of five fish that significantly selected the negative stimulus more frequently than chance were trained in the red versus yellow discrimination, with red as the positive stimulus. This was further confirmed by the individual analyses (Table 1), in which we found that two subjects that exhibited a significant preference for the colour red continued to select this non-rewarded stimulus throughout the experiment. On the contrary, no subject that showed a significant choice for the rewarded stimulus exhibited a spontaneous preference for any colour at the beginning of the experiment. 
Table 1. Frequency of correct choices and binomial tests in the colour discrimination task. Asterisks denote a significant departure from chance.

\begin{tabular}{cccccc}
\hline Subjects & $\begin{array}{c}\text { Colour } \\
\text { Discrimination }\end{array}$ & $\begin{array}{c}\text { Positive } \\
\text { Colour }\end{array}$ & $\begin{array}{c}\text { Spontaneous } \\
\text { Preference at the } \\
\text { First 40 Trials? } \\
\text { Binomial Tests }\end{array}$ & $\begin{array}{c}\text { Frequency of } \\
\text { Correct Choices }\end{array}$ & Binomial Tests \\
\hline 1 & Red vs. Yellow & Yellow & NO $(P=0.636)$ & $274 / 500$ & $P=0.035^{*}$ \\
2 & Red vs. Yellow & Yellow & NO $(P=0.875)$ & $272 / 500$ & $P=0.054$ \\
3 & Red vs. Yellow & Red & NO $(P=0.636)$ & $128 / 500$ & $P<0.001^{*}$ \\
4 & Red vs. Yellow & Red & YES $(P=0.017)$ & $152 / 500$ & $P<0.001^{*}$ \\
5 & Red vs. Yellow & Yellow & NO $(P=0.636)$ & $297 / 500$ & $P<0.001^{*}$ \\
6 & Red vs. Yellow & Red & NO $(P=0.154)$ & $143 / 500$ & $P<0.001^{*}$ \\
7 & Green vs. Blue & Blue & NO $(P=0.875)$ & $254 / 500$ & $P=0.754$ \\
8 & Green vs. Blue & Blue & NO $(P=0.081)$ & $229 / 500$ & $P=0.067$ \\
9 & Green vs. Blue & Blue & YES $(P=0.002)$ & $135 / 500$ & $P<0.001^{*}$ \\
10 & Green vs. Blue & Green & NO $(P=0.154)$ & $242 / 500$ & $P=0.502$ \\
11 & Green vs. Blue & Green & NO $(P=0.430)$ & $348 / 500$ & $P<0.001^{*}$ \\
12 & Green vs. Blue & Green & NO $(P=0.430)$ & $270 / 500$ & $P=0.081$ \\
13 & Red vs. Yellow & Yellow & NO $(P=0.430)$ & $284 / 500$ & $P=0.003 *$ \\
14 & Red vs. Yellow & Red & NO $(P=0.430)$ & $144 / 500$ & $P<0.001^{*}$ \\
15 & Green vs. Blue & Blue & NO $(P=0.268)$ & $240 / 500$ & $P=0.396$ \\
16 & Green vs. Blue & Green & NO $(P=0.268)$ & $273 / 500$ & $P=0.044^{*}$ \\
\hline
\end{tabular}

\section{Scototaxis Test}

Zebrafish spent more time in the darker half of the tank (proportion of time spent in the darker area: $0.582 \pm 0.023$, one-sample $t$-test $t(15)=3.611, p=0.030, d=0.903$ ). In this area, a larger proportion of movements were observed $(0.570 \pm 0.025, t(15)=2.836, p=0.013, d=0.709)$. A significant correlation was found between the proportion of time spent in the darker half and the proportion of movements made in the same area $(r=0.955, p<0.001)$. As personality factors are known to be related to sex (reviewed in [54]), we analysed whether there was any difference between males and females. No difference was found (proportion of time spent in the darker area: males $0.587 \pm 0.020$, females $0.578 \pm 0.039, t(14)=0.211, p=0.836, d=0.290$; proportion of movements in the darker area: males $0.584 \pm 0.029$, females $0.558 \pm 0.038, t(14)=0.519, p=0.612, d=0.769$ ).

No correlation was found between scototaxis measures and overall accuracy in the colour discrimination task (proportion of time spent in the darker area and overall accuracy, $r=-0.060$, $p=0.825$; proportion of movements in the darker area and overall accuracy, $r=0.007, p=0.979$; see Figure 3).

(a)

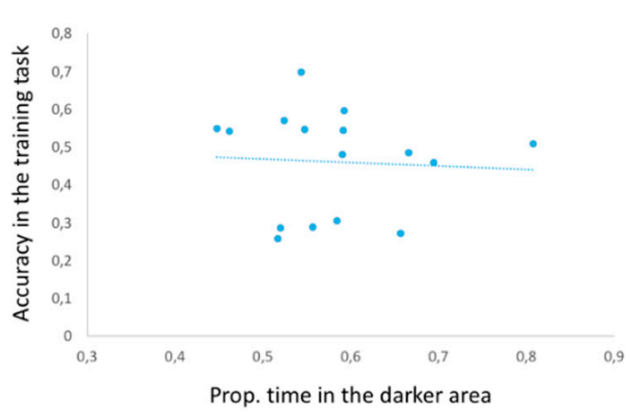

(b)

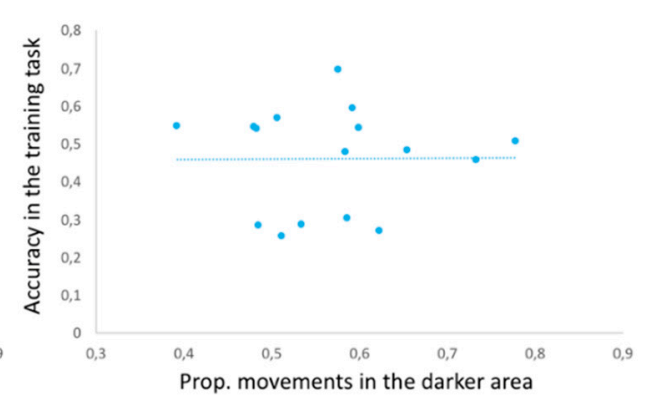

Figure 3. Correlation between scototaxis and accuracy in the colour discrimination task. No significant correlation was found either when considering the proportion of time spent in the darker area (a) or when considering the proportion of movements in the darker area of the scototaxis test (b). 


\section{Detour Test}

As expected from previous literature [11-14], most individuals were poorly, if at all, lateralized. Indeed, individual analyses showed four strongly lateralized individuals: two right detour (subjects 2 and 10) and two left detour (subjects 12 and 15). Group analysis confirmed that our subjects were mainly not lateralized $(-8.750 \pm 9.995$, one-sample $t$-test with chance level $=0, t(15)=-0.875, p=0.395$, $d=0.219)$. No difference between males $(5.710 \pm 49.952)$ and females $(-20.000 \pm 28.284)$ was found $(t(14)=1.306, p=0.213, d=0.633)$.

We did not find a significant correlation between overall accuracy in the colour discrimination task and the different degree of lateralization $(r=0.018, p=0.947$, see Figure 4$)$. Also, no correlation was found between the lateralization index and the two scototaxis measures (proportion of time spent in the darker area and lateralization index: $r=0.394, p=0.131$; proportion of movements in the darker area and lateralization index: $r=0.400, p=0.125$ ).

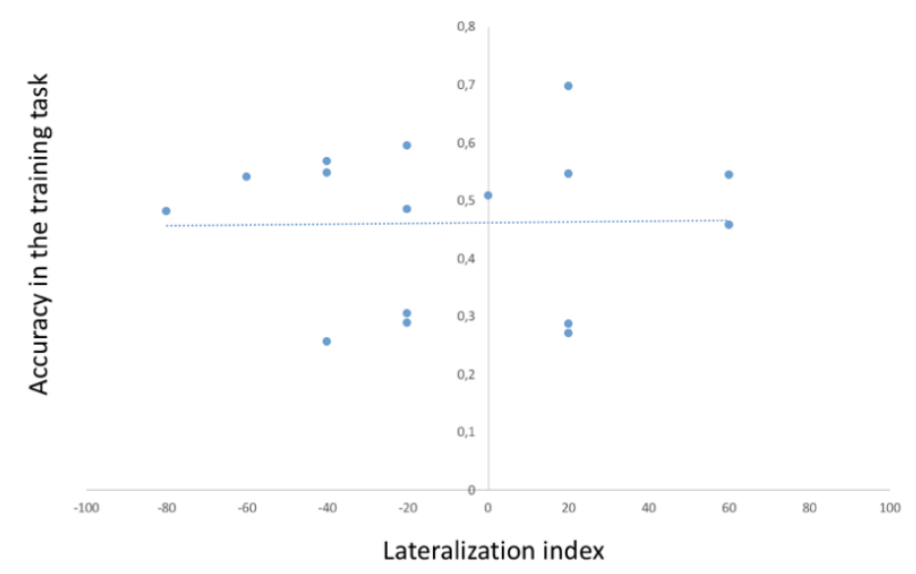

Figure 4. Correlation between lateralization index and accuracy in the colour discrimination task. No significant correlation was found between performance in these two tasks.

Outlier Removal in the Correlational Analyses

Inspection of boxplots revealed only one outlier in the proportion of time spent near the darker area (scototaxis test). To assess whether the results of correlational analyses were affected by the behaviour of this subject (subject 7 of Table 1), we removed the outlier and reanalysed the correlations that involved the proportion of time spent near the darker area. The same conclusions were found. No correlation was found between the performance in the colour discrimination task and the proportion of time spent in the darker area $(r=-0.163, p=0.561)$. No correlation was found between lateralization index and the proportion of time spent in the darker area $(r=0.476, p=0.964)$, whereas we reported a positive correlation between the proportion of movements in the darker area and the proportion of time spent in the darker area $(r=0.941, p<0.001)$.

Bayes Factor Analyses

Correlational analyses did not show any significant relationship between the performance in the learning task, the degree of brain lateralization, and anxiety-like behaviour. However, when no significant correlation between two groups are found, it remains possible that a true correlation might exist between the groups but the task was not precise enough to detect it. To test the strength of our conclusions, we used an alternative statistical approach and calculated Bayes factors for correlational analyses [55]. This analysis enables researchers to estimate the relative strength of the evidence for two competing hypotheses (H0: the two variables do not correlate to each other; $\mathrm{H} 1$ : a positive/negative correlation does exist) [56]. The approximate Bayes factor indicated the hypothesis of no correlation between learning skills and brain lateralization/anxiety-like behaviour was at least five times more likely than the alternative hypothesis (see Table 2). 
Table 2. Bayes factors of correlational analyses. Bayesian factors higher than 3 are commonly considered moderate/strong evidence for the hypotheses that are supported by the $p$-value approach [55].

\begin{tabular}{cc}
\hline Correlation & Bayes Factor \\
\hline Colour discrimination task-scototaxis (time) & 5.168 \\
Colour discrimination task—scototaxis (movements) & 5.294 \\
Colour discrimination task-detour test & 5.284 \\
Detour test—scototaxis (time) & $\mathbf{1 . 6 9 6}$ \\
Detour test-scototaxis (movements) & $\mathbf{1 . 6 3 5}$ \\
\hline
\end{tabular}

\section{Discussion}

The present study aimed to test the impact of brain lateralization and anxiety-like behaviour in the learning skills of a model species commonly used in genetics, neuroscience, and translational studies. To achieve this goal, we tested zebrafish in a Skinner box that permitted us to administer hundreds of trials for each individual and correlated their performance in the detour test (as a measure of lateralization) and scototaxis (as a measure of anxiety). We did not find any evidence in favour of a link between lateralization, scototaxis, and learning skills in zebrafish.

Lateralization in fish has been found to positively influence performance in dual tasks [51] and numerical tasks [9,10], but has no effect on escape response [15] and has a negative effect when fish are required to quickly transfer visual information between the two brain hemispheres before making a decision about which shoal to join [16]. The lack of correlation found here between degree of lateralization and performance in the colour discrimination task suggests that lateralization does not have a deep impact on learning skills. It is possible that, given the fundamental role of learning skills to face most problems encountered in nature, the capacity to learn associations between stimuli is equally effective in lateralized and non-lateralized individuals. This result is potentially important for translational studies. Indeed, even though in several species_-including zebrafish [48]—individuals largely differ in terms of their degree of brain lateralization, this variable has often been neglected in operant conditioning studies. Discovering that the performance in a prolonged operant conditioning task is not related to the degree of lateralization should help in genetic studies, as it guarantees that the genes associated with learning skills in zebrafish are not associated with brain lateralization (a fact that would represent a confounding result). For instance, several authors have suggested that a disturbance in the lateralization process, controlled by genes, could be crucial for the development of schizophrenia. Although the molecular link between lateralization and schizophrenia is far from being fully understood, partly overlapping genes can be responsible for this association [57,58].

Concerning the measure of anxiety, we found that zebrafish exhibited a spontaneous preference for the darker half of the tank $[59,60]$, with no difference as a function of sex. This behavioural strategy probably reflects a conflict between the preference for protected, darker areas and a natural motivation to explore novel environments [41]. The inter-individual variability found in the scototaxis test did not correlate with performance in the learning task, meaning that the capacity to undergo an extensive operant conditioning training was not related to the different anxiety levels of subjects. Again, we believe that such a conclusion is important for the ongoing screening of cognitive abilities of zebrafish. For instance, the fact that this personality trait is not related to performance in a Skinner box could help us to maximize the chance to identify candidate genes of cognitive skills (for instance, LIMK1 and MMP7 for learning spatial and numerical tasks $[61,62]$ ) and not the genes underlying anxiety traits that, in turn, affect learning tasks.

Interestingly, we did not find any significant correlation between lateralization and scototaxis either. This result aligns with the recent study on zebrafish [17] showing no correlation between lateralization and anxiety-like behaviour. The two studies adopted different experimental paradigms to assess lateralization and anxiety-like behaviour. For what concern lateralization, we observed the asymmetrical tendency to monitor a potential predator with the two halves of the brain, one of the most used tests for brain lateralization in fish [9,16,52]. Fontana et al. [17] used a Y-maze task, that is, the 
observation of free movements in a maze, to test pure motor lateralization. With respect to anxiety-like behaviour, we used the light/dark test, which exploits the natural preference for a dark environment (scototaxis response) over a light one, whereas Fontana et al. [17] used the novel tank diving test in which the degree of bottom dwelling is interpreted as an index of anxiety. It was argued that these behavioural tasks are complementary rather than interchangeable [63]. Therefore, the similar result of the two studies does corroborate the conclusion of a lack of relation between brain lateralization and anxiety-like behaviour in zebrafish, instead of being the consequence of the use of a specific experimental procedure.

One may argue that the lack of significant correlation was due to a limited sample size. Indeed, although power analysis permitted us to preliminarily assess the appropriate sample size, four subjects ceased to participate throughout the learning task. We must acknowledge that this might have reduced the chance of detecting significant correlations among the colour discrimination task, detour test, and scototaxis test. That being said, the results of the Bayes factors largely supported the null results of correlational analyses in that they indicated that the lack of correlations between these variables was at least five times more likely than the alternative hypothesis.

It is worth noting that the performance of zebrafish was overall poor in the colour discrimination task. Individual analyses showed that almost one-third of the subjects $(31 \%)$ learned the colour discrimination in our experimental design. The analysis of the first trials of the training showed, however, that none of these subjects exhibited a spontaneous preference of any colour; hence, their overall performance did reflect the result of a learning process. Why then did our subjects show poor performance in a colour discrimination task after an extensive training-one that used at least an eightfold higher number of trials compared to most previous literature in operant conditioning studies in fish (e.g., [64])—while they clearly discriminated among these colours using different types of tasks $[34,65]$ ? The small/moderate effect size of the overall analysis of the training suggested that the present procedure may not be fully appropriate to test learning skills in this species. Some methodological issues should be taken into account. The nature of the stimuli, for instance, differs among the different experimental contexts. In the case of Colwill et al. [65], all three walls of the arms were coloured; this perceptual cue might have been more salient compared to our $2 \times 2 \mathrm{~cm}$ stimuli. Oliveira et al. [34] used three-dimensional objects, and we cannot exclude that these stimuli might have been more ecological than two-dimensional stimuli. Furthermore, in our study, food was provided in the opposite position of the stimuli to ensure that fish swam near the initiator light, a fundamental condition to start the new trial at an equal distance from the two colours. While Oliveira et al. [34] did not use food as reward, Colwill et al. [65] rewarded fish in correspondence of the positive colour. The possibility exists that the different location of food reward (in correspondence of/opposite to the stimuli) might have impacted the overall performance. Other methodological factors should be taken into consideration to improve our training - the use of a correction procedure might help to increase the association between the target colour and the reward [66]. Also, because fish were taken from a commercial store, we only had limited control of their previous experience (with the exception of the three months preceding the beginning of the experiment). This might have represented a confounding factor.

Lastly, fish are cold-blooded vertebrates that can be easily satiated. Previous studies on colour discrimination tasks in zebrafish were largely based on a limited amount of trials (and consequently food per experimental session) each day $[34,65]$. Here, we used an innovative automated operant conditioning procedure that permitted us to present hundreds of trials, but we cannot exclude that, even though we delivered a very limited amount of food for each correct trial, the extensive operant conditioning procedure that characterizes Skinner boxes is intrinsically less efficient in cold-blooded vertebrates compared to mammals and birds, which can often reach $80 \%-90 \%$ accuracy and are even able to perform thousands of trials $[67,68]$. It is worth noting that our subjects were also fed once a day in their home tanks because a similar feeding schedule was successfully used in other cognitive tasks with fish $[69,70]$. In the case of our extensive training, however, this might have reduced the motivation 
to search for food. A recent study showed that a different fish species, goldfish, can perform even thousands of trials in a Skinner box [71], raising the possibility that a prolonged training - together with a different feeding schedule in their home tanks-might have improved the performance of zebrafish in this operant conditioning task.

To summarize, the operant conditioning procedure adopted to investigate learning skills in this study was found to be only partially effective, a fact that prevents the drawing of firm conclusions. However, the inter-individual variability here observed in learning skills was not related to anxiety-like behaviour in facing the experimental setup, nor was it associated with different degrees of lateralization in the detour test, a fact that does not encourage the hypothesis of a link between learning skills, brain lateralization, and anxiety in this animal model.

Supplementary Materials: The following are available online at http://www.mdpi.com/2073-8994/11/11/1395/s1.

Author Contributions: M.E.M.P. and C.A. designed the study; M.D. set up the experimental apparatuses; A.P. collected and analyzed the data; M.E.M.P, and C.A. wrote the first draft of the manuscript. All authors approved the final version of the manuscript.

Funding: This research was funded by PRIN grant no. 2015' (prot.: 2015FFATB7) from 'Ministero dell'Istruzione, Università e Ricerca' (MIUR, Italy) to C. Agrillo and by Marie Skłodowska-Curie individual fellowship (SBCN1E4R) from the European Union's Horizon 2020 to M. E. Miletto Petrazzini.

Acknowledgments: The authors wish to thank Alessia Damini and Linda Gambaretto for their help in testing the animals. The present work was carried out within the scope of the research program Dipartimenti di Eccellenza (art.1, commi 314-337 legge 232/2016), which was supported by a grant from MIUR to the Department of General Psychology, University of Padua.

Conflicts of Interest: The authors declare no conflict of interest.

\section{References}

1. Dunaif-Hattis, J. Doubling the Brain; Lang: New York, NY, USA, 1984.

2. Levy, J. The mammalian brain and the adaptive advantage of cerebral asymmetry. Ann. N. Y. Acad. Sci. 1977, 299, 264-272. [CrossRef] [PubMed]

3. Rogers, L.J. Evolution of hemispheric specialization: Advantages and disadvantages. Brain Lang. 2000, 73, 236-253. [CrossRef] [PubMed]

4. Rogers, L.J. Advantages and disadvantages of lateralization. In Comparative Vertebrate Lateralization; Rogers, L.J., Andrew, R.J., Eds.; Cambridge University Press: Cambridge, UK, 2002; pp. 126-154.

5. Gunturkun, O.; Diekamp, B.; Manns, M.; Nottelmann, F.; Prior, H.; Schwarz, A.; Skiba, M. Asymmetry pays: Visual lateralization improves discrimination success in pigeons. Curr. Biol. 2000, 10, 1079-1081. [CrossRef]

6. McGrew, W.C.; Marchant, L.F. Laterality of hand use pays off in foraging success for wild chimpanzees. Primates 1999, 40, 509-513. [CrossRef]

7. Pascual, A.; Huang, K.L.; Neveu, J.; Preat, T. Brain asymmetry and long-term memory. Nature 2004, 427, 605-606. [CrossRef] [PubMed]

8. Rogers, L.J.; Zucca, P.; Vallortigara, G. Advantages of having a lateralized brain. Proc. R. Soc. Lond. B 2004, 271, S420-S422. [CrossRef] [PubMed]

9. Gatto, E.; Agrillo, C.; Brown, C.; Dadda, M. Individual differences in numerical skills are influenced by brain lateralization in guppies (Poecilia reticulata). Intelligence 2019, 74, 12-17. [CrossRef]

10. Dadda, M.; Agrillo, C.; Bisazza, A.; Brown, C. Laterality enhances numerical skills in the guppy, Poecilia reticulata. Front. Behav. Neurosci. 2015, 9, 285. [CrossRef] [PubMed]

11. Bisazza, A.; Cantalupo, C.; Robins, A.; Rogers, L.; Vallortigara, G. Pawedness and motor asymmetries in toads. Laterality 1997, 1, 161-175. [CrossRef] [PubMed]

12. Bisazza, A.; Facchin, L.; Vallortigara, G. Heritability of lateralization in fish: Concordance of right-left asymmetry of detour responses between parents and offspring. Neuropsychologia 2000, 38, 907-912. [CrossRef]

13. Clotfelter, E.D.; Kuperberg, E.S. Cerebral lateralization and its relationship to phylogeny and aggression in anabantoid fishes. Brain Behav. Evol. 2007, 69, 169-175. [CrossRef] [PubMed]

14. Takeuchi, Y.; Hori, M. Behavioural laterality in the shrimp-eating cichlid fish Neolamprologus fasciatus in Lake Tanganyika. Anim. Behav. 2008, 75, 1359-1366. [CrossRef] 
15. Agrillo, C.; Dadda, M.; Bisazza, A. Escape behaviour elicited by a visual stimulus. A comparison between lateralised and non-lateralised female topminnows. Laterality 2009, 14, 300-314. [CrossRef] [PubMed]

16. Dadda, M.; Zandonà, E.; Agrillo, C.; Bisazza, A. The costs of hemispheric specialization in a fish. Proc. R. Soc. Lond. B 2009, 276, 4399-4407. [CrossRef] [PubMed]

17. Fontana, B.D.; Cleal, M.; Clay, J.M.; Parker, M.O. Zebrafish (Danio rerio) behavioral laterality predicts increased short-term avoidance memory but not stress-reactivity responses. Anim. Cogn. 2019. [CrossRef] [PubMed]

18. Griffin, A.S.; Guillette, L.M.; Healy, S.D. Cognition and personality: An analysis of an emerging field. Trends Ecol. Evol. 2015, 30, 207-214. [CrossRef] [PubMed]

19. Eysenck, M.W.; Derakshan, N.; Santos, R.; Calvo, M.G. Anxiety and cognitive performance: Attentional control theory. Emotion 2007, 7, 336-353. [CrossRef] [PubMed]

20. Toxopeus, I.B.; Sterck, E.H.M.; Jan, A.R.A.M.; van Hooff, A.M.; Spruijt, B.M.; Heeren, T.J. Effects of trait anxiety on performance of socially housed monkeys in a learning test. Behaviour 2005, 142, 1269-1287.

21. Walf, A.A.; Paris, J.J.; Frye, C.A. Chronic estradiol replacement to aged female rats reduces anxiety-like and depression-like behavior and enhances cognitive performance. Psychoneuroendocrinology 2009, 34, 909-916. [CrossRef] [PubMed]

22. Dooley, K.; Zon, L.I. Zebrafish: A model system for the study of human disease. Curr. Opin. Genet. Dev. 2000, 10, 252-256. [CrossRef]

23. Bakkers, J. Zebrafish as a model to study cardiac development and human cardiac disease. Cardiovasc. Res. 2011, 91, 279-288. [CrossRef] [PubMed]

24. Brennan, C.H. Zebrafish behavioural assays of translational relevance for the study of psychiatric disease. Rev. Neurosci. 2011, 22, 37-48. [CrossRef] [PubMed]

25. Tropepe, V.; Sive, H.L. Can zebrafish be used as a model to study the neurodevelopmental causes of autism? Genes Brain Behav. 2003, 2, 268-281. [CrossRef] [PubMed]

26. Kalueff, A.V.; Stewart, A.M.; Gerlai, R. Zebrafish as an emerging model for studying complex brain disorders. Trends Pharmacol. Sci. 2014, 35, 63-75. [CrossRef] [PubMed]

27. Karnik, I.; Gerlai, R. Can zebrafish learn spatial tasks? An empirical analysis of place and single CS-US associative learning. Behav. Brain Res. 2012, 233, 415-421. [CrossRef] [PubMed]

28. Agrillo, C.; Miletto Petrazzini, M.E.; Tagliapietra, C.; Bisazza, A. Inter-specific differences in numerical abilities among teleost fish. Front. Psychol. 2012, 3, 483. [CrossRef] [PubMed]

29. Hamilton, T.J.; Myggland, A.; Duperreault, E.; May, Z.; Gallup, J.; Powell, R.A.; Schalomon, M.; Digweed, S.M. Episodic-like memory in zebrafish. Anim. Cogn. 2016, 19, 1-9. [CrossRef] [PubMed]

30. Lindeyer, C.M.; Reader, S.M. Social learning of escape routes in zebrafish and the stability of behavioural traditions. Anim. Behav. 2010, 79, 827-834. [CrossRef]

31. Ostlund, S.B.; Balleine, B.W. Selective reinstatement of instrumental performance depends on the discriminative stimulus properties of the mediating outcome. Learn. Behav. 2007, 35, 43-52. [CrossRef] [PubMed]

32. Putz, G.; Bertolucci, F.; Raabe, T.; Zars, T.; Heisenberg, M. The S6KII (rsk) gene of Drosophila melanogaster differentially affects an operant and a classical learning task. J. Neurosci. 2004, 24, 9745-9751. [CrossRef] [PubMed]

33. Brembs, B. Spontaneous decisions and operant conditioning in fruit flies. Behav. Proc. 2011, 87, $157-164$. [CrossRef] [PubMed]

34. Oliveira, J.; Silveira, M.; Chacon, D.; Luchiari, A. The zebrafish world of colors and shapes: Preference and discrimination. Zebrafish 2015, 12, 166-173. [CrossRef] [PubMed]

35. Vallortigara, G.; Regolin, L.; Pagni, P. Detour behaviour, imprinting and visual lateralization in the domestic chick. Cogn. Brain Res. 1999, 7, 307-320. [CrossRef]

36. Ferrari, M.C.; McCormick, M.I.; Allan, B.J.; Choi, R.B.; Ramasamy, R.A.; Chivers, D.P. The effects of background risk on behavioural lateralization in a coral reef fish. Funct. Ecol. 2015, 29, 1553-1559. [CrossRef]

37. Chivers, D.P.; McCormick, M.I.; Warren, D.T.; Allan, B.J.; Ramasamy, R.A.; Arvizu, B.K.; Glue, M.; Ferrari, M.C.O. Competitive superiority versus predation savvy: The two sides of behavioural lateralization. Anim. Behav. 2017, 130, 9-15. [CrossRef]

38. Dadda, M.; Koolhaas, W.H.; Domenici, P. Behavioural asymmetry affects escape performance in a teleost fish. Biol. Lett. 2010, 6, 414-417. [CrossRef] [PubMed] 
39. Sovrano, V.A.; Baratti, G.; Potrich, D. A detour task in several species of fishes. Front. Psychol. 2018, 9, 2341. [CrossRef] [PubMed]

40. Bourin, M.; Hascoët, M. The mouse light/dark box test. Eur. J. Pharmacol. 2003, 463, 55-65. [CrossRef]

41. Maximino, C.; Brito, T.M.; Dias, C.A.G.M.; Gouveia, A.; Morato, S., Jr. Scototaxis as anxiety-like behavior in fish. Nat. Prot. 2010, 5, 221-228. [CrossRef] [PubMed]

42. Prut, L.; Belzung, C. The open field as a paradigm to measure the effects of drugs on anxiety-like behaviors: A review. Eur. J. Pharmacol. 2003, 463, 3-33. [CrossRef]

43. Sechzer, J.A.; Brown, J.L. Color discrimination in the cat. Science 1964, 144, 427-429. [CrossRef] [PubMed]

44. Savage, A.; Dronzek, L.A.; Snowden, C.T. Color discrimination by the cotton-top tamarin (Saguinus oedipus oedipus) and its relation to fruit coloration. Folia Primatol. 1987, 49, 57-69. [CrossRef] [PubMed]

45. Giurfa, M. Conditioning procedure and color discrimination in the honeybee Apis mellifera. Naturwissenschaften 2004, 91, 228-231. [CrossRef] [PubMed]

46. Lucon-Xiccato, T.; Bisazza, A. Discrimination reversal learning reveals greater female behavioural flexibility in guppies. Biol. Lett. 2014, 10, 20140206. [CrossRef]

47. Agrillo, C.; Piffer, L.; Bisazza, A. Number versus continuous quantity in numerosity judgments by fish. Cognition 2011, 119, 281-287. [CrossRef] [PubMed]

48. Dadda, M.; Domenichini, A.; Piffer, L.; Argenton, F.; Bisazza, A. Early differences in epithalamic left-right asymmetry influence lateralization and personality of adult zebrafish. Behav. Brain Res. 2010, 206, 208-215. [CrossRef] [PubMed]

49. Facchin, L.; Argenton, F.; Bisazza, A. Lines of Danio rerio selected for opposite behavioural lateralization show differences in anatomical left-right asymmetries. Behav. Brain Res. 2009, 197, 157-165. [CrossRef] [PubMed]

50. Barth, K.A.; Miklosi, A.; Watkins, J.; Bianco, I.H.; Wilson, S.W.; Andrew, R.J. Fsi zebrafish show concordant reversal of laterality of viscera, neuroanatomy, and a subset of behavioral responses. Curr. Biol. 2005, 15, 844-850. [CrossRef] [PubMed]

51. Dadda, M. Lateralized female topminnows can forage and attend to a harassing male simultaneously. Behav. Ecol. 2006, 17, 358-363. [CrossRef]

52. Facchin, L.; Bisazza, A.; Vallortigara, G. What causes lateralization of detour behaviour in fish? Evidence for asymmetries in eye use. Behav. Brain Res. 1999, 103, 229-234. [CrossRef]

53. Moretz, J.A.; Martins, E.P.; Robison, B.D. Behavioral syndromes and the evolution of correlated behavior in zebrafish. Behav. Ecol. 2007, 18, 556-562. [CrossRef]

54. Weinstein, T.A.R.; Capitanio, J.P.; Gosling, S.D. Personality in animals. In Handbook of Personality: Theory and Research; John, O.P., Robins, R.W., Pervin, L.A., Eds.; The Guilford Press: New York, NY, USA, 2008; pp. 328-348.

55. Raftery, A.E. Bayesian model selection in social research. Sociol. Methodol. 1995, 25, 111-163. [CrossRef]

56. Dienes, Z. Using Bayes to get the most out of non-significant results. Front. Psychol. 2014, 5, 781. [CrossRef] [PubMed]

57. Ocklenburg, S.; Güntürkün, O.; Hugdahl, K.; Hirnstein, M. Laterality and mental disorders in the postgenomic age-A closer look at schizophrenia and language lateralization. Neurosci. Biobehav. Rev. 2015, 59, 100-110. [CrossRef] [PubMed]

58. Dragovic, M.; Hammond, G. Handedness in schizophrenia: A quantitative review of evidence. Acta Psychiatr. Scand. 2005, 111, 410-419. [CrossRef] [PubMed]

59. Serra, E.L.; Medalha, C.C.; Mattioli, R. Natural preference of zebrafish (Danio rerio) for a dark environment. Braz. J. Med. Biol. Res. 1999, 32, 1551-1553. [CrossRef] [PubMed]

60. Maximino, C.; Brito, T.M.; Moraes, F.D.; Oliveira, F.V.C.; Taccolini, I.B.; Pereira, P.M.; Colmanetti, R.; Lozano, R.; Gazolla, R.A.; Tenório, R.; et al. A comparative analysis of the preference for dark environments in five teleosts. Int. J. Comp. Psychol. 2007, 20, 351-367.

61. Gray, V.; Karmiloff-Smith, A.; Funnell, E.; Tassabehji, M. In-depth analysis of spatial cognition in Williams syndrome: A critical assessment of the role of the LIMK1 gene. Neuropsychologia 2006, 44, 679-685. [CrossRef] [PubMed]

62. Kanzafarova, R.F.; Kazantseva, A.V.; Khusnutdinova, E.K. Genetic and environmental aspects of mathematical disabilities. Russ. J. Genet. 2015, 51, 223-230. [CrossRef] 
63. Maximino, C.; Benzecry, R.; Oliveira, K.R.M.; Batista, E.D.J.O.; Herculano, A.M.; Rosemberg, D.B.; Oliveira Batista, E.D.J.; Herculano, A.M.; Matos Oliveira, K.R.; Benzecry, R.; et al. A comparison of the light/dark and novel tank tests in zebrafish. Behaviour 2012, 149, 1099-1123. [CrossRef]

64. Agrillo, C.; Miletto Petrazzini, M.E.; Bisazza, A. Numerical abilities in fish: A methodological review. Behav. Proc. 2017, 141, 161-171. [CrossRef] [PubMed]

65. Colwill, R.M.; Raymond, M.P.; Ferreira, L.; Escudero, H. Visual discrimination learning in zebrafish (Danio rerio). Behav. Process. 2005, 70, 19-31. [CrossRef] [PubMed]

66. Gatto, E.; Lucon-Xiccato, T.; Savasci, B.B.; Dadda, M.; Bisazza, A. Experimental setting affects the performance of guppies in a numerical discrimination task. Anim. Cogn. 2017, 20, 187-198. [CrossRef] [PubMed]

67. Brannon, E.M.; Wusthoff, C.J.; Gallistel, C.R.; Gibbon, J. Numerical subtraction in the pigeon: Evidence for a linear subjective number scale. Psychol. Sci. 2001, 12, 238-243. [CrossRef] [PubMed]

68. Cantlon, J.F.; Brannon, E.M. Shared system for ordering small and large numbers in monkeys and humans. Psychol. Sci. 2006, 17, 401-406. [CrossRef] [PubMed]

69. Miletto Petrazzini, M.E.; Agrillo, C.; Izard, V.; Bisazza, A. Do humans (Homo sapiens) and fish (Pterophyllum scalare) make similar numerosity judgments? J. Comp. Psych. 2016, 130, 380-390. [CrossRef] [PubMed]

70. Lucon-Xiccato, T.; Santacà, M.; Miletto Petrazzini, M.E.; Agrillo, C.; Dadda, M. Guppies, Poecilia reticulata, perceive a reversed Delboeuf illusion. Anim. Cogn. 2019, 22, 291-303. [CrossRef] [PubMed]

71. Shinozuka, K.; Ono, H.; Watanabe, S. Reinforcing and discriminative stimulus properties of music in goldfish. Behav. Proc. 2013, 99, 26-33. [CrossRef] [PubMed]

(C) 2019 by the authors. Licensee MDPI, Basel, Switzerland. This article is an open access article distributed under the terms and conditions of the Creative Commons Attribution (CC BY) license (http://creativecommons.org/licenses/by/4.0/). 